\title{
MARKETING DE RELACIONAMENTO: QUAIS SUAS DIRETRIZES E COMO AS EMPRESAS AS UTILIZAM PARA A CAPTAÇÃO E FIDELIZAÇÃO DE CLIENTES
}

doi $10.33726 /$ akedia2447-7656v8a52019p57-71

ALVES, Rafael ${ }^{1}$

ALEXANDRE, Kethi Cristina do Rosário Squecola²

CARVALHO, Celso Almeida de ${ }^{3}$

RESUMO: O presente estudo se preocupa em dimensionar o traçado do eventual descompasso entre as transformações sociais, tecnológicas e as adaptações solicitadas às empresas neste contexto para se manterem competitivas no mercado. Nesse cenário, o sucesso pode se vincular a estratégias como as previstas pelo marketing de relacionamento, por meio do qual se deve saber identificar essas mudanças, posto que apresenta ferramentas de apoio à criação de valor para os clientes da organização. A partir de uma abordagem histórica da linha evolutiva do marketing, pode-se perceber que o mercado exigiu que a mercadologia sofresse uma mutação, a fim de que pudesse atender às expectativas dos consumidores, agora, mais exigentes e críticos em sua relação com os serviços e produtos oferecidos. Como corpus desta análise do marketing de relacionamento, adotamos a captação e a fidelização de clientes. Como resultado desta investigação, evidenciou-se a relevância do marketing de relacionamento dentro desse panorama, sendo que o mesmo consegue proporcionar benefícios para ambas as partes da relação e assim, fortalecer as empresas e a consequente obtenção de implicações satisfatórias e mais competitivas.

PALAVRAS-CHAVE: Marketing de relacionamento; Clientes; Captação; Fidelização.

\begin{abstract}
This study has a perspective on the dimensions of the path of a possible mismatch between social, technological and adaptive transformations for companies in this context to remain competitive in the market. In this scenario, success can be linked to strategies such as those envisioned by relationship marketing, through which to identify these changes, and the tools that support the creation of value for the organization's customers. From a historical approach to the evolutionary line of marketing, it can be seen that the marketplace required that the marketplace mutate so that it could meet the expectations of the now more demanding and service-critical consumers. and products offered. As a corpus of this relationship marketing analysis, we adopted customer acquisition and loyalty. As a result of this investigation, the relevance of relationship marketing within this scenario was evidenced, and it can provide benefits for both parts of the relationship and thus strengthen companies and consequently obtain satisfactory and more competitive implications.
\end{abstract}

KEYWORDS: Relationship marketing; Customers; Captation; Loyalty.

\footnotetext{
${ }^{1}$ MBA em Gestão Empresarial pela Universidade Paulista - UNIP. Contato: rafael.alves@ cclinet.com.br

${ }^{2}$ Mestre em Gestão em Saúde e em Enfermagem. Docente da Universidade Paulista (UNIP), de São José do Rio Preto/SP. Contato: kethicris@ hotmail.com

${ }^{3}$ Bacharel em Administração pela UNIFEB. Contato: celsouemg@ hotmail.com
} 


\section{INTRODUÇÃO}

O cenário globalizado e tecnológico em que a sociedade atual se encontra, é bombardeado por um excesso de informações, apelos e novas ofertas que surgem frequentemente no mercado. Dessa maneira, é essencial, para a manutenção e crescimento de uma organização, que ela saiba gerir a sua clientela, além de ser capaz de manter os seus clientes atuais e conquistar futuros consumidores.

Cabe às empresas, determinar o seu diferencial competitivo nos mercados em mutação, definir suas estratégias de sustentabilidade, e desenvolver a capacidade de suprir relações firmes e duradouras com os clientes. É essencial dar a devida importância a dois princípios vitais na gestão organizacional e no planejamento estratégico das empresas: a captação e a fidelização.

O marketing é fundamental para o sucesso de qualquer empreendimento, pois permite que o cliente seja conquistado em todas as etapas da venda, criando uma relação mútua de confiança, com comunicação transparente e totalmente direcionada.

Por isso, a mercadologia de relacionamento visa manter-se em constante contato com a as dinâmicas de transformação dos mercados e dos clientes, por meio de um conjunto de estratégias de construção e difusão das marcas, de prospecção, de fidelização e de criação de autoridade no mercado, tornando a empresa viável em uma relação em longo prazo com os seus clientes, fixando seus produtos e serviços na mente dos consumidores.

Neste sentido, este estudo tem como objetivo, analisar panoramicamente 0 mercado atual, as necessidades que as empresas possuem para se manterem ativas e relevantes no presente cenário, e traçar a importância que o marketing de relacionamento pode representar para a consolidação da eficácia do seu funcionamento.

\section{REFERENCIAL TEÓRICO: HISTÓRIA E EVOLUÇÃO DO MARKETING DE RELACIONAMENTO}

O marketing está intimamente ligado à história da humanidade e à sua evolução. Já, nas premissas da Revolução Industrial, a partir de 1780, momento em que se deu início à concorrência das empresas para oferecerem seus produtos pelo menor preço do mercado, notou-se que a produção industrial não poderia ser 
independente, isto é, não se daria sem levar em consideração as necessidades e desejos dos consumidores.

Para Horquen (2009, p. 13), o desenvolvimento industrial proporcionou a ampliação dos mercados e do capitalismo industrial, cedendo espaço ao capitalismo financeiro, fazendo surgir, assim, instituições financeiras e os bancos.

No fim da I Guerra Mundial, após 1918, houve um avanço industrial de grandes proporções, devido aos excedentes de produção bélica, os quais necessitavam ser escoados dos estoques, visto que sem o advento da Guerra, cada vez mais se acumulavam.

Dessa forma, a concentração foi total em promover e vender tudo aquilo que foi produzido, mesmo que não fosse necessariamente o que o mercado necessitava comprar.

Com o fim da II Guerra Mundial, em 1945, começaram a se aplicar as estratégias de guerra ao campo mercadológico. Assim, novos materiais, fontes de energia, tecnologias e canais de comunicação entraram na cena do mercado, o que levou a uma sofisticação dos produtos e dos processos de produção, enquanto que, ao mesmo tempo, houve uma queda nos padrões de consumo e perda do poder aquisitivo da população, devido à escassez de recursos, contingência natural num pós-guerra.

Assim, as propagandas começaram a fazer uso de apelos mais psicológicos, fortalecendo-se nelas práticas mercadológicas. Essa época ficou conhecida como a "Era das Vendas", que durou até cerca de 1950, e nesse panorama, surgiram as primeiras táticas de campanhas publicitárias, como propagandas, promoções de vendas e vendas pessoais, para tentar encontrar clientes para que fossem ávidos pelos estoques ainda não vendidos.

No Brasil, o marketing se iniciou efetivamente na década de 50 do século $X X$, com uma economia dominada pelos setores comercial e agrícola, e com os consumidores ainda não habilitados ao consumo de produtos industriais refinados. As mercadorias eram consumidas sem se questionar a sua qualidade, e com uma demanda passiva e pouco criteriosa.

Esse contexto começou a se alterar, no final de década de 1960, alavancado pelo crescimento de um mercado jovem, que estava insaciável pelo lançamento de novas mercadorias. De acordo com Oliveira (2004, p. 39), a industrialização levou ao aumento da oferta de produtos. Surgiram os "produtos-vedete", como os 
eletrodomésticos, entre eles o aparelho de televisão, fazendo crescer a concorrência, o que, por sua vez, levou os profissionais de mercado a se preocuparem cada vez mais com o consumidor. O marketing de relacionamentos passou, então, a não mais ser centrado no produto, e sim na tática orientada ao consumidor.

Um fato a ser destacado nesse período, é a criação, nos Estados Unidos, do "Código de Defesa do Consumidor" (com a criação do Consumers Union, em 1930), que passou a ser protegido por Leis específicas, regendo condutas no sentido de que as empresas respondessem pelas reclamações e exigências dos consumidores, sendo esse um dos primeiros marcos a ajudar a desenvolver o conceito de marketing de relacionamentos na compreensão contemporânea da expressão.

A década de 1970 balizou o início da mudança na forma de pensar e agir dos consumidores, que começaram a comparar preços, ficarem mais atentos à qualidade dos produtos e a se preocuparem mais com o orçamento familiar, passando o cerne do marketing a ser a propaganda, e não mais apenas as vendas.

O governo, as organizações civis, as entidades religiosas e os partidos políticos passaram a valer-se das estratégias mercadológicas, adaptando-as às suas realidades e necessidades. Segundo Oliveira (2004, p. 39), as empresas começaram a definir seu público-alvo por meio de estratégias de segmentação e com o apoio de pesquisas de mercado. A ideia dominante era a de que diferentes grupos de consumidores possuíam diferentes perfis e interesses, e estes precisavam ser identificados e atendidos. A maneira de se fazer isso era comunicando-lhes a existência do produto certo, por meio da publicidade.

Na década de 1980, os consumidores passaram a ser mais seletivos, devido aos altos índices de inflação e de corrosão salarial. Desse modo, o marketing começou a ser de responsabilidade não apenas de um setor da empresa, mas, sim, da alta Direção das companhias, visto que os estudos de mercado eram capazes de integrar todos os departamentos de uma organização em busca de fazê-la atingir os seus objetivos. Nessa época, então, é que surgiu mais fortemente o pensamento sobre marketing de relacionamento, inicialmente focado na lealdade, na satisfação e na retenção de clientes, com a meta de criar relacionamentos duradouros e com benefícios para ambos.

Na década de 1990, segundo Miranda \& Arruda (2004, p. 50), houve um avanço no pensamento do marketing de relacionamentos. Neste período, a consciência 
empresarial se postou sobre a necessidade de construir relacionamentos cooperativos com outras organizações, como maneira de assegurar a própria competitividade. Com isso, se motivou a especulação teórica sobre a formação, desenvolvimento e manutenção de parcerias com clientes, fornecedores e distribuidores.

Como principais transformações da época, Horquen (2009, p. 15) ressalta as seguintes fronteiras: acirramento da concorrência devido à globalização; surgimento de novas tecnologias; revolução nas comunicações através da utilização do computador, que possibilitou o comércio virtual através da internet; e a crescente consciência tecnológica por parte da sociedade.

As linhas de pensamento mais recentes a surgirem na mercadologia datam do início dos anos 2000: o cybermarketing, com foco na personalização em massa, na rapidez das transações e na alta interatividade com os clientes; e o marketing experiencial, focado nas sensações que os produtos proporcionam aos seus usuários, e não somente nas necessidades.

Nota-se, então, como o foco atual do marketing está pautado nos relacionamentos e na vivência do consumidor com o produto ou serviço. Essa linha evolutiva do conceito de marketing está esquematizada na Figura 2, trazendo as características principais de cada época, bem como as vertentes de pensamento desenvolvidas dentro de cada período.

Figura 2 - Evolução do marketing

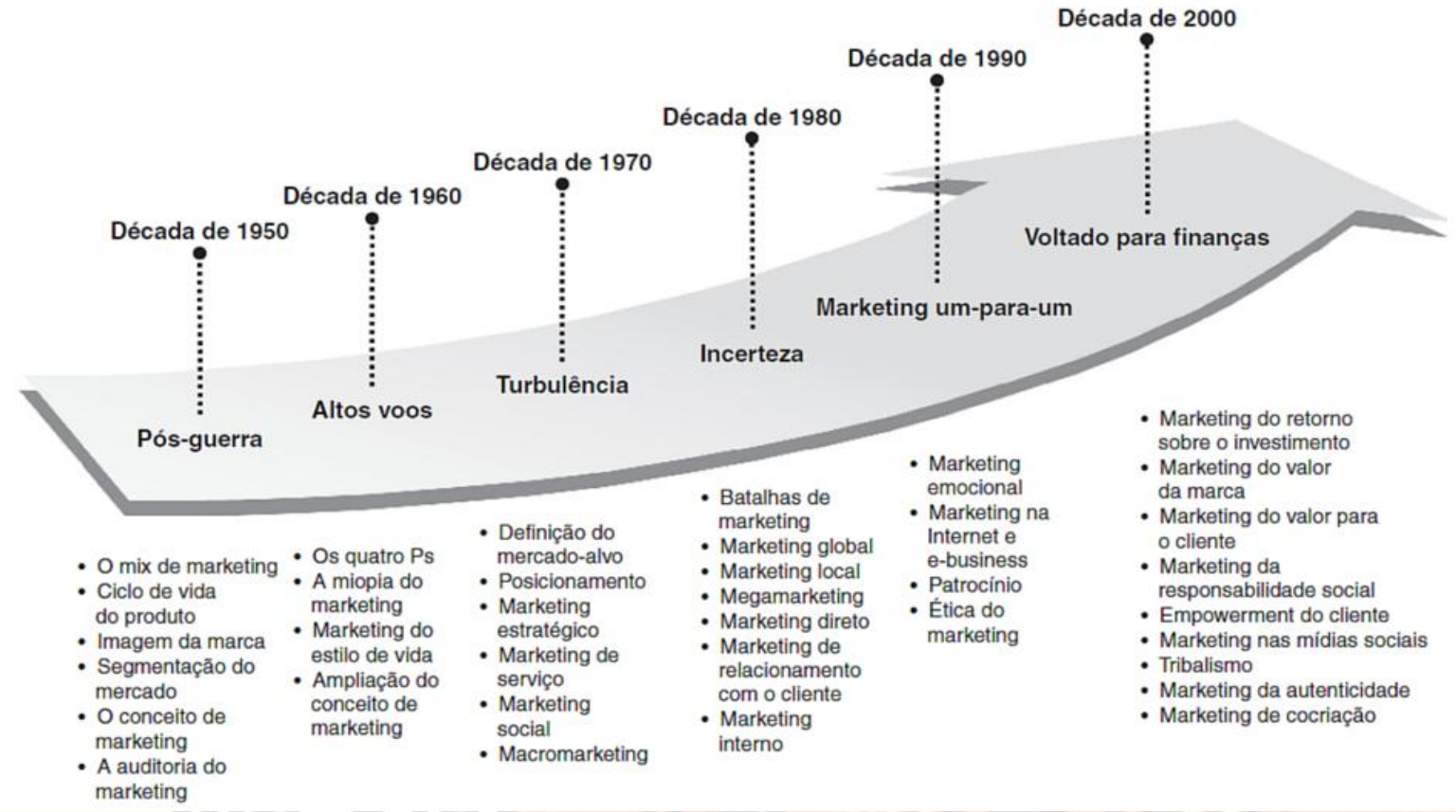

Fonte: Kotler, Kartajaya e Setiawan (2010, p. 32) 


\section{Os tipos de clientes}

O cliente é conceituado como a pessoa que adquire produtos ou serviços das organizações, quer seja para consumo próprio, quer para a distribuição, sendo o cliente a pessoa mais importante para qualquer tipo de negócio. É a razão pela qual um empreendimento entra em exercício; é o motivo pelo qual as empresas mantém suas portas abertas. Os principais tipos de clientes que uma empresa possui, e que o marketing deve ser capaz de atingir, são: cliente externo, interno, da concorrência e cliente pessoal.

O cliente externo é aquele que sofre o impacto direto dos produtos e serviços oferecidos pelas empresas, pagando por eles sem participar do processo de produção. É aquele que mantem a empresa financeiramente, ao adquirir seus produtos e mão de obra, desejando ter as suas necessidades correspondidas com serviços de valor e qualidade. Assim, Bogmann (2000, p. 37), propôs uma tipologia do cliente externo, de acordo com o perfil de sua fidelidade, a ser conhecida:

$\checkmark$ Prospects: pessoas que podem estar interessadas em comprar de uma empresa;

$\checkmark$ Shoppers: pessoas que visitaram a empresa pelo menos uma vez;

$\checkmark$ Clientes eventuais: pessoas que adquiriram um ou mais produtos ou serviços da empresa;

$\checkmark$ Clientes regulares: pessoas que adquirem regularmente os produtos ou serviços de determinada organização; e,

$\checkmark$ Defensores: pessoas que elogiam a qualidade do negócio a quem quiser ouvir.

O cliente interno é todo aquele que faz parte do dia a dia do ambiente de trabalho, seja em qualquer área ou hierarquia da empresa, desde que influencie no processo produtivo e no fornecimento de serviços, sendo a chave mestra para a qualidade total do negócio. Para Marques (1997, p. 152), o cliente interno é o principal responsável pela qualidade percebida pelo cliente externo e pelo corrente de clientes internos.

Logo, o marketing de relacionamento começa já dentro da empresa, pois se a corporação deseja conquistar a fidelidades dos seus clientes, precisa primeiro valorizar e fidelizar os internos. Quando um cliente dialoga com algum funcionário da empresa, imagina dialogar com a própria empresa, por isso, os clientes internos devem estar 
totalmente aptos a atendê-los com atenção e respeito, tendo autonomia e responsabilidade para poder falar em nome da empresa.

Não se aceita mais que uma empresa se concentre no seu cliente, sem que haja a mesma atenção para com seus funcionários, a opinião do cliente interno é tão valiosa quanto a do externo. Bogmann (2000, p. 40) elenca outros fatores determinantes para a criação de uma mentalidade de cooperação entre os clientes internos:

$\checkmark$ Criação de uma declaração de valores e de visão da empresa;

$\checkmark$ Envolvimento dos funcionários;

$\checkmark$ Desenvolvimento de um processo de clientes internos;

$\checkmark$ Desenvolvimento de habilidades de cooperação;

$\checkmark$ Criação de ambientes competitivos positivos;

$\checkmark$ Criação de uma estrutura organizacional que apoie o trabalho com os clientes; e,

$\checkmark$ Criação de uma infraestrutura que apoie o trabalho com os clientes, sendo o ponto central o sistema de reconhecimento e recompensa.

Os clientes da concorrência são os que não compram de uma empresa, e sim da sua concorrente. Juntamente com os clientes externos formam a massa de clientes ativos conhecidos como mercado atual. É de suma importância fazer uma avaliação desse tipo de cliente, para descobrir o que os leva a comprar da concorrência, e conseguir uma forma de conquista-los.

A concorrência pode ainda ser dividida em dois grupos: os concorrentes diretos, que são aqueles que oferecem os mesmos produtos e serviços, na mesma faixa de preço, e com pontos de vendas semelhantes, atingindo o mesmo público-alvo; e os concorrentes indiretos, que são os que não oferecerem o mesmo tipo de produto ou serviço, mas que atingem o mesmo perfil de público-alvo através de estratégias que acabam por influenciar na decisão final do consumidor, ou seja, são concorrentes em nível institucional.

\section{O cliente como pilar do marketing de relacionamento}

O cliente é o pilar da mercadologia de relacionamentos da organização. Com o cliente se deve construir uma parceria permanente, oferecendo-lhe valor e satisfação, mantendo as transações nível elevado de qualidade para estimular a fidelidade e a 
satisfação, de modo que se atinja a satisfação do cliente ante de se buscar o lucro e a rentabilização corporativa.

Segundo McKenna (1997, p. 45), o posicionamento do marketing de relacionamento começa com o consumidor analisando o que pensam sobre os produtos e empresas, comparando-os com outros produtos e empresas.

Um dos principais pontos que deve ser levado em consideração ao se estudar o relacionamento entre marketing e clientes, é que é cinco vezes mais caro recrutar novos clientes do que manter os que já existem, situação essa que pode ocasionar problemas no orçamento de qualquer empresa:

Hoje, as empresas de maior destaque fazem de tudo para manter seus clientes. Muitos mercados atingiram a maturidade, e não há muitos clientes novos para se captar. A competição é cada vez maior, e os custos para atrair novos clientes sobem cada vez mais. Nesses mercados poderia custar até cinco vezes mais atrair um novo cliente do que custa manter um cliente atual satisfeito. Um marketing agressivo custa mais do que um marketing defensivo, pois exige um enorme investimento para afastar os clientes satisfeitos dos concorrentes e ganhá-los para si (BOGMANN, 2000, p. 47).

Portanto, deve haver um cuidado especial com a perda de clientes, buscandose sempre medidas que reduzam esse índice de deserção. Faz-se necessário identificar o motivo que origina essa perda, pois clientes que abandonaram a empresa por motivo de satisfação podem ser recuperáveis, desde que se adote a correta solução para o estancamento do problema.

Um cliente não se tornará satisfeito apenas por ter feito uma boa compra, mas, sim, por toda a experiência vivida, desde o momento em que é concebido o negócio, passando pela solução do problema enfrentado pelo cliente. Assim, o atendimento oferecido, os aspectos comerciais e a capacidade de negociação, a velocidade em que tal problema foi solucionado, e a reincidência da qualidade contam.

Segundo De Nascimento (2012, p. 28), existe, portanto, uma relação causal entre a qualidade de um produto ou serviço e a satisfação do cliente, sendo que a qualidade antecede a satisfação, ao se pressupor, dentro do contexto descrito, a qualidade como o atendimento das expectativas, e a satisfação, como resultado dos benefícios que realmente são recebidos pelo cliente.

De acordo com Klein (2009, p. 39), um atendimento falho põe em risco todos os esforços e recursos empreendidos numa campanha de marketing de 
relacionamentos. É preciso investir tempo e dinheiro em uma adequada estrutura de atendimento, pois é aí que se firma a boa imagem da empresa, que se consolida a conquista do cliente e, principalmente, que se fazem negócios.

Para tanto é preciso estar atento aos oito componente do marketing de relacionamento. Gordon (1999, p. 45), então, elenca os oito componentes principais do marketing de relacionamento, que devem estar ajustados entre a empresa e seus clientes. Quais sejam; 1) culturas e valores; 2) liderança; 3) estratégia; 4) estrutura; 5) pessoal; 6) tecnologia; 7) conhecimento e percepção; e, 8) processos.

Segundo Monteiro (2003, p. 35), o marketing de relacionamento convida o cliente para dentro da empresa, por meio da cadeia de valor. Com ele, apaga-se a linha que limita onde começa o cliente e onde termina a empresa. Assim, a empresa se organiza de maneira diferente, muda seu sistema de incentivos e procura transformar todos os demais aspectos da rotina administrativa para torná-la mais capaz de ligar-se intensamente aos seus clientes, envolvendo-os no desenvolvimento do produto, construindo uma agregação de vantagens individuais e personalizadas, se concentrando nos processos e em tudo aquilo que é necessário para o aprimoramento dos relacionamentos.

\section{Customer Relationship Management}

Para sustentar as estratégias do marketing de relacionamento desenvolvidas pelas empresas, é que surgiu, no universo empresarial, o conceito de CRM "Customer Relationship Management" - que é que uma expressão aplicada para o gerenciamento do relacionamento com o cliente, sendo mais do que simples softwares, mas, sim, uma ferramenta que capta a essência dos sistemas informatizados que ajudam nessa tarefa, antecipando as necessidades e potenciais da empresa, além de exigir uma mudança de comportamento organizacional:

Compreende-se que essa tecnologia é a primeira tarefa de uma organização para que ela possa ter êxito no mercado, atrair e fidelizar seus clientes, pois só assim poderá sobreviver no mercado atual tão competitivo. As organizações devem saber gerenciar ao máximo as diferenças existentes entre a variedade de clientes que sua empresa trabalha, para que possam entender cada um deles, agradando da melhor forma possível, como se fosse o único, ou o último cliente da face da terra (CASTRO, 2015, p. 02). 
O CRM surgiu, inicialmente, na década de 70 , a partir de programas simples que realizavam o auxílio aos relacionamentos. A partir da década de 1990, as empresas lançaram mão desse sistema para auxiliar o gerenciamento geral dos clientes, devido à alta demanda por tecnologias que otimizavam esse quadro.

Ao longo dos anos, diversas funcionalidades foram se incorporando a esses softwares, que atualmente são extremamente comuns e necessários no meio empresarial (SANTOS et al., 2009).

O CRM, por sua vez, pode ser dividido em 04 tipos:

$\checkmark$ CRM operacional: visa os canais de relacionamento, atuando como interface e integração dos sistemas de back-office e front-office, incluindo automação da força de vendas, marketing empresarial e suporte ao cliente;

$\checkmark$ CRM analítico: utiliza os dados e informações coletados dos clientes, para analisar comportamento, correlações, e tendências, gerando assim conhecimento voltado aos negócios para implementação das estratégias;

$\checkmark$ CRM colaborativo: integra as demais funções, através de serviços colaborativos como edição personalizada, e-mails, comunidades, conferências, e centros de interação, com foco em promover a comunicação entre os diversos setores de marketing da empresa, para obtenção do valor do cliente; e,

$\checkmark$ CRM estratégico: utiliza dos outros tipos para definir planos de ação, idealizar novos produtos, serviços ou promoções, segmentação de cliente, e tudo mais que envolve atingir os objetivos definidos pela empresa, através de uma análise de tecnologia e usabilidade.

Para que o CRM seja implantado com sucesso pelas organizações, Zenone (2007), e Peppers, Rogers (2004), demonstram algumas ferramentas que são indispensáveis, e que devem estar diretamente integradas a todo o processo:

$\checkmark$ ERP - "Enterprise Resource Planning": são sistemas integrados de gestão empresarial, cujo objetivo é o controle e provimento de suporte aos processos operacionais, produtivos, administrativos e comerciais dentro de uma empresa;

$\checkmark$ Data Warehouse: é um banco de dados responsável por integrar e gerenciar as informações dos bancos de dados corporativos, dessa forma, tornando-os acessíveis em tempo real para o seu gerenciamento e uso;

$\checkmark$ Data Mining: tem como fonte de dados o data warehouse, identificando tendências, anomalias e as correlações entre um cliente específico e outros clientes, abrangendo dessa forma três áreas de uso: associação entre produtos, identificação de clientes com potencial para gerar maior lucro, e fidelização;

$\checkmark$ SFA - "Sales Force Automation": tem como objetivo automatizar algumas etapas do processo de vendas, forçando a disciplina na aceitação aos processos determinados 
pela organização. Abrange diversos gerenciamentos, como contatos, contas, oportunidades, processos de vendas, previsão de vendas, orçamentos e pedidos;

$\checkmark$ EMA - "Enterprise Marketing Automation": é o sistema de automação do marketing, que deve contemplar funcionalidades como gerência de campanhas, personalização de perfis, e outras fontes de dados e acompanhamento de permissões, para aumentar a produtividade das atividades que geram demanda, aumentam a receita, produzem mais leads e de melhor qualidade, reduzindo os custos e o tempo de execução de tarefas; e, $\checkmark$ Call Center: sendo uma das principais ferramentas para o desenvolvimento das relações com os clientes, seu objetivo principal é dominar todas as particularidades do contato com 0 cliente, englobando as atividades de respostas às perguntas, solicitações de suporte e outros contatos além das vendas propriamente ditas.

Não existe uma fórmula pronta e $100 \%$ eficaz para se implementar o CRM em uma organização, pois a empresa, assim como o mercado, passa por diversos processos de mudança ao longo do tempo, que devem ser levados em consideração, pois cada um deles terá o seu papel no processo de implementação (PEPPERS, ROGERS, 2005).

Madruga (2004), descreve algumas etapas importantes que devem ser seguidas nesse processo, sendo que essas podem ser aplicadas tanto para empresas de pequeno como de grande porte, pois todas elas necessitam de uma metodologia: planejamento para a prática, treinamento dos recursos internos, design e análise da solução, construção da solução, treinamento do usuário final, teste e homologação do que foi construído, fase de produção e acompanhamento da produção e relatório final. Deve-se analisar, também, o comportamento do sistema diante de um grande volume de dados que estão sendo trafegados.

\section{Estratégias para captar e fidelizar clientes através do marketing de relacionamento}

Devem-se traçar estratégias que visem à conquista, aumento e manutenção de clientes rentáveis por um período maior de tempo, identificando os que estão propensos a iniciar um relacionamento com a companhia, ou aqueles que estão tendendo a abandoná-la, fixando ações que os reconquistem e fortaleçam a sua fidelidade. Neste sentido, Gronroos (1993) estabeleceu quatro estratégias básicas para a eficácia os processos em uma organização: 
$\checkmark$ Qualidade técnica: uma qualidade técnica superior de um produto ou serviço é fundamental para a relevância de uma empresa, funcionando a sua excelência técnica como valor crítico para os clientes;

$\checkmark$ Preço: a precificação dos produtos de uma empresa é o seu diferencial competitivo, devendo nesse caso, ter cuidado especial ao observar os preços da concorrência, para a manutenção do valor dos seus produtos para seus clientes;

$\checkmark$ Imagem: utiliza-se de anúncios ou outros meios de comunicação para a construção de uma imagem da empresa, que será o seu diferencial competitivo; e,

$\checkmark$ Serviços: relaciona-se com a habilidade da empresa de servir seus clientes de forma competitiva, através de ofertas diferenciadas no mercado.

Outra estratégia a ser adotada para a captação e fidelização, diz respeito ao contato dos clientes com os vendedores, o feedback necessário, difundir novidades sobre seus produtos, que possam ser de interesse aos seus consumidores, através da análise sobre as aquisições anteriores que eles possam ter com a empresa e estudar o que está sendo oferecido pela concorrência, e assim, ter a capacidade de se manter atualizado (KOTLER, 1998).

Há alguns erros básicos cometidos pelas empresas que influenciam na possibilidade dos processos de captar e de fidelizar, fazendo-as não obterem sucesso: falta de objetivos, não gastar o tempo correto com o cliente para conseguir sua fidelização, atendimento não compatível com a expectativa criada pelo usuário no relacionamento, falta de análise dos resultados obtidos, e deixar pesquisas para a última instância.

Nesses dois últimos itens, é notória a necessidade de apoiarmo-nos na análise de alguns números, como: quantidade de clientes que retornam à empresa, aumento do número de vendas, aumento do número de clientes que se relacionam ativamente, a capacidade de concluir se os resultados estão sendo satisfatórios ou não na captação de clientes, e a possibilidade de obter melhorias nos programas de fidelização.

Segundo De Carvalho, Maia e Santos (2012, p. 66), é preciso se estabelecer metas financeiras, pois um plano de fidelização de clientes pode levar anos para chegar ao ponto de equilíbrio, trazendo, assim, resultado à empresa.

$E$, conforme o exposto até aqui, podemos afirmar que a influência do marketing de relacionamento nos processos de captação e fidelização de clientes está pautada em cinco pilares: 1) definição dos objetivos; 2) identificação das necessidades dos clientes; 3) desenvolvimento de uma correta abordagem para a comunicação; 4) 
definição da segmentação do público-alvo; e, 5) investimento no treinamento dos funcionários.

\section{CONSIDERAÇÕES FINAIS}

Com o presente estudo foi possível identificar que as empresas que desejam se manter relevantes no mercado competitivo, investem suas forças em um planejamento de marketing de relacionamento que aplica eficazmente estratégias certeiras, orientadas para a atração e retenção de clientes.

O marketing de relacionamento acompanha os avanços, cria e identifica valor para os usuários de determinada empresa. Estes usuários são os mesmos que passam a ditar as regras das negociações atuais e, por isso, as ações de planejamento devem sempre estar centradas na satisfação dos mesmos.

É determinante para a eficácia do marketing de relacionamento que todos os setores e pessoas da empresa caminhem para o mesmo objetivo final, num processo ininterrupto de cooperação. É fundamental que estejam alinhados com as principais ferramentas e diretrizes orientadoras do processo, como o CRM e o composto de marketing.

A fidelização é evidente, um cliente fiel é um dos pilares para o crescimento das instituições, tanto organizacionalmente quanto financeiramente, já que se torna mais barato manter um consumidor do que tentar conquistar algum novo prospect.

O marketing de relacionamento tem como sua essência principal no desenvolvimento de uma boa relação entre empresa e cliente, fundada numa relação que beneficie ambos. Por fim, deve-se atentar para o fato de que, tanto o marketing de relacionamento quanto os processos de captação e fidelização, não devem ser apenas um pedaço da empresa, mas, sobretudo, a razão de elas existirem. 


\section{REFERÊNCIAS}

BOGMANN, I. M. Marketing de relacionamento: estratégias de fidelização e suas implicações financeiras. São Paulo: Nobel, 2000

CASTRO, D. J. O. A importância do CRM - Customer Relationship Management dentro do universo empresarial para o desenvolvimento de estratégias de marketing de relacionamento por parte das empresas. Revista Pensar Gestão e Administração, v.3, n.2, jul. 2015.

DE CARVALHO, Ana Lúcia Lima; MAIA, Cláudia Aparecida; SANTOS, Michele Carolina dos. Captação e retenção de clientes. Revista Científica do Unisalesiano, Lins, São Paulo, ano 3, n. 7, jul./dez. 2012.

DO NASCIMENTO, Edivan José. A importância do marketing de relacionamento para uma empresa de pequeno porte. 62 fls. 2012. Monografia (Bacharel em Administração) - Universidade Federal da Paraíba, João Pessoa, Paraíba, 2012.

GORDON, I. Marketing de relacionamento: estratégias, técnicas e tecnologias para conquistar clientes e mantê-los para sempre. São Paulo: Futura, 1999

GRONROOS, C. Marketing: gerenciamento e serviços - a competição por serviços na hora da verdade. Rio de Janeiro: Campus, 1993

HORQUEN, C. E. L. (Re) visitando os conceitos do marketing: da sociedade de massa à comunidade virtual. 66fls. Monografia (Bacharel em Publicidade) - UNIFRACentro Universitário Franciscano, Santa Maria, RS, 2009.

KLEIN, Wemerson Robert Nunes. Marketing de relacionamento: estudo de caso "café do doutor". Dissertação (Mestrado em Administração) Fundação Cultural Dr. Pedro Leopoldo, Pedro Leopoldo MG, 2009.

KOTLER, P. Administração de marketing: análise, planejamento, implementação e controle. 5.ed. São Paulo: Atlas, 1998.

KOTLER, P.; KARTAJAYA, H.; SETIAWAN, I. Marketing 3.0: as forças que estão definindo o novo marketing centrado no ser humano. Rio de Janeiro: Elsevier, 2010.

MADRUGA, R. Guia de Implementação de Marketing de Relacionamento e CRM. São Paulo: Editora Atlas S.A, 2004.

MARQUES, F. Guia Prático da Excelência em serviços: como conquistar clientes, aumentar os lucros e viver melhor. São Paulo: Nobel,1997.

MIRANDA, Claudia Maria Carvalho; ARRUDA, Danielle Miranda de Oliveira. A evolução do pensamento de marketing: uma análise do corpo doutrinário acumulado no século XX. Revista Interdisciplinar de Marketing, v. 3, n. 1, p. 40-57, 2015.

MCKENNA, R. Marketing de relacionamento: Estratégias bem-sucedidas para a era do cliente. 25 ed. Rio de Janeiro: Elsevier, 1997. 
MONTEIRO, Marcos Cruz WAlsh. Marketing de relacionamento: proposta de um plano de marketing de relacionamento para a Genyus Baterias. $147 \mathrm{fls}$. 2003. Dissertação (Mestre em Administração) - Fundação Getúlio Vargas, Rio de Janeiro, 2003.

OLIVEIRA, Sérgio Ricardo Góes. Cinco décadas de marketing. GV-executivo, v. 3, n. 3, p. $37-43,2004$.

PEPPERS, D.; ROGERS, M. CRM séries - marketing 1to1: aumentando o valor de seus clientes com CRM. São Paulo: Material Peppers and Rogers Group, Brasil, 2004.

PEPPERS, D.; ROGERS, M. Retorno sobre clientes: um modo revolucionário de medir e fortalecer o seu negócio. Rio de Janeiro: Elsevier, 2005.

SANTOS, T. et. al. O desenvolvimento do marketing: uma perspectiva histórica. Revista de Gestão USP, São Paulo, v. 16, n. 1, p. 89-102, jan./mar. 2009.

ZENONE, L. C. CRM - Customer Relationship Management: gestão do relacionamento com o cliente e a competitividade empresarial. São Paulo: Novatec Editora, 2007. 